\title{
Literature Review of Faculty-perceived Usefulness of Instructional Technology in Classroom Dynamics
}

\author{
Alexandra Salas \\ Mercer County Community College, United States
}

\begin{abstract}
This article provides a literature review of the research concerning the role of faculty perspectives about instructional technology. Learning management systems, massive open online courses (MOOCs), cloud-based multimedia applications, and mobile apps represent the tools and the language of academia in the $21^{\text {st }}$ century. Research examined illustrates how important understanding user attitudes can be in the technology deliberation process. Consequently, the faculty opinions should not be underestimated in technology acceptance discussions as coupled with ongoing education technological developments is the challenge of innovation adoption.
\end{abstract}

Keywords: e-tools, Distance Education; Faculty-perceived usefulness; Voice-authoring tools; Instructional technology

\section{Introduction}

Classrooms of the $21^{\text {st }}$ century share the spotlight with massive open online learning courses (MOOCs), online and hybrid formats that reach students through sophisticated web-based learning management systems. Along with these new academic developments are competing instructional technology options that make innovation adoption decisions challenging. The research examined includes narratives about education technology trends from the mid- $20^{\text {th }}$ century and user beliefs that can help in the technology deliberation process (Nicolle \& Lou, 2008, p. 238). For example, the Large-Group Instruction Room (LGI), a state-of-the art facility developed in the 1960s at Stanford University, was equipped with a pull-down screen, suspended television monitors, a lectern, a glassenclosed technicians station, and student-responders (or clickers) that enabled students replies to instructor questions. The technicians "could assist the professor with amplification of sound, simultaneous interpretation of various languages, slide or film presentation and overhead projection of data" (Cuban, 2001, p. 99). Decades later, the structure remains, although it is not used as initially designed. Cuban (2001) asked why the facility was inoperable as intended and found that faculty were not included in the conception and execution of this state-of-the-art idea. While Cuban noted how faculty may have used technology for their own research, the "teachers used them infrequently and altered their conventional forms of teaching very little" (p. 103), which suggests how knowledge of faculty-perceived usefulness toward the technology could help to foresee whether or not investment in technology was warranted. Cuban concluded that decisions to equip schools with technology, while well intentioned, were not based deliberations by potential users 
about the innovation's perceived usefulness (p. 158). To optimize integration of an instructional innovation, this finding supported that idea that stakeholder input about perceived usefulness is essential. Examining perceived usefulness can "help inform the broader conversation about teaching, learning and tertiary institutional transformation against a backdrop of widespread digitization, changing student demographics, and increased market competition" (LeBaron \& McFadden, 2008, p. 144). This notion about perceived usefulness is evident in scholarly articles about technology integration in education.

To investigate this issue, the researcher reviewed electronic library databases and GoogleScholar to locate peer-reviewed and academic articles that would provide insight on research concerning faculty-perceived usefulness about e-tools in the classroom. The search words used combined with faculty or education included the following: e-tools, perception, attitudes, perceived usefulness, voice authoring, Voice over Internet protocol, multimedia tools, distance learning, and online teaching and ICT. Databases referenced were Academic Search Premier, ERIC, EbscoHost, and ProQuest. The following themes were identified from the scholarly articles reviewed: facultyperceived usefulness of e-tools, faculty input and inclusion, purposeful technology, and ease of use.

\section{Faculty-Perceived Usefulness and the Technology Acceptance Model (TAM)}

According to the Technology Acceptance Model (TAM), perception, specifically perceived usefulness of a given innovation, affects user intention to engage. In TAM, perceived usefulness and perceived ease of use are beliefs that are presumed to (a) influence attitudes toward new technology and (b) mediate the relationship between external variables and attitude (Porter \& Donthu, 2006, p. 1000). Graham and Jones (2011) noted how faculty experiences contribute to behavior attitudes and outcomes. In a study of 115 faculty at a state university, Graham and Jones found that positive experiences with the technology correlate with faculty-perceived usefulness of distance education. Graham and Jones stated, "The responses also validate prior research showing that lack of administrative and technical support as well as lack of meaningful incentives, especially in the promotion and tenure reviews, still had a negative impact on perceptions of distance education" ( $p$. 219). Framing faculty notions about instructional technologies based on these theories can offer insight regarding the influence of perceived usefulness on education technology use. Wherever the process of change leads, it can begin with the exchange and inclusion of perspectives.

In the process of affecting academic change, faculty should have the opportunity to weigh in. Enumerated on their technology adoption process checklist, Harasim, Hiltz, Teles, and Turoff (1995) encouraged "user participation in the planning ...listen to the questions and reported problems and doubts that prospective online instructors have...and identify enthusiastic early adopters...they can become mentors to other faculty" (pp. 171-172). In addition, workshops or discussion forums that offer communication opportunities are tantamount when technology integration is being considered. Harasim et al. (1995) stated, "Faculty members also gain from group discussions of common problems and from joking and interacting with their peers" (p. 163). These exchange platforms can provide a place where faculty can share their views. 
Lei and Gupta (2010) discussed the many advantages of distance education perceived by faculty, however, they also addressed the perceived costs, classroom effectiveness, information overload, and the need for faculty patience and willingness to deal with students who may need more attention. Among the faculty issues cited, Lei and Gupta included, "Negative attitude of instructors toward online technology, temporarily removing instructors from their comfort zone and [faculty difficulty in assessing] students' affective traits" (p. 628). It follows that inclusion strategies point to more successful technology adoption because they tend to consider the reservations and desires of the potential user population.

Steel and Hudson (2001) reported a dearth in the research concerning faculty-perceived usefulness toward technology. Steel and Hudson (2001) submitted that

there have been relatively few studies that have sought a qualitative account of lecturers' perceived usefulness and experiences of educational technology which look at everyday accounts of educational technology, which is combined with an insight into broader political, social, cultural and institutional factors which also impact on the learning environment and their experiences as educators. (p. 103)

What began as a project to evaluate student experiences with education technologies at Sheffield Hallam University in the U.K. developed to include faculty-perceived usefulness. Eleven faculty participated in recorded interviews and the results were thematically organized. Themes relevant to this study focused on "notions of value or benefits of educational technology; teacher and students' roles and relationships; the perceived drawbacks of using educational technology and perception of social, cultural and institutional forces" (Steel \& Hudson, 2001, p.104). Drawbacks reported by Steel and Hudson included "the awareness of and unease at the fast rate of technological innovation...coupled with pressure to stay abreast of new innovations, the notion that technology could in fact threaten meaningful face-to-face interaction which is perceived as crucial" (p. 106). In addition, other faculty comments concerned a sense of professional dislocation and institutional pressures. "The main area of complaint was centered around the fragility of technology and appropriate support for the development of educational technologies...[and] communication at all levels of higher education [being] paramount in learning and teaching innovation and development" (Steel \& Hudson, 2001, p. 110). These findings undergird the role communication in instruction technology adoption discussions.

Using the TAM, Abuhamdieh and Sehwail (2007) examined student and faculty perspectives about ease of use and usefulness in a study about a campus portal adoption. "The study used a [26question] survey instrument for data collection, and the ANOVA statistical analysis was used on interval data to uncover any differences between faculty and student attitudes and portal use patterns. For nominal data, the Chi square test was used" (p. 42). Student participants numbered 2,400 and 400 faculty were randomly selected to complete survey that was posted online of which 209 and 42 faculty responded (p. 42). In this example, the portal was composed of a "bulletin board, news, announcements, and distance education modules" (p. 44). Abuhamdieh and Sehwail found that understanding faculty-perceived usefulness was instrumental to education technology's survival and acceptance by others. Abuhamdieh and Sehwail (2007) stated:

User acceptance of a technology necessitates the presence of both ease of use and usefulness from the perspective of the prospective user... Special attention should be paid to faculty training and acceptance of portals, since they act as opinion leaders and role 
models for students. In fact, they are the ones who will demonstrate the use of portals to students, and the use of any particular module that they will subsequently use in their classes, such as BB or e-groups. (p. 47)

Given the opportunity to test drive innovation, the influence of user experiences as a change agent should not be underestimated.

In a study conducted at six Turkish universities, Akbulut, Odabasi, and Kuzu (2011) examined "the views of pre-service teachers" toward education technology tools, and supported the view that understanding perceived usefulness influences information communication technology use. More than 2,600 graduating student participants completed the 75-item questionnaire. Akbulut, Odabasi, and Kuzu (2011) explained that "negative opinions regarding policy indicated that administrators were unsuccessful in implementing constructive programs and policies to improve student [future faculty] attitudes" (p. 178). Similarly, in an empirical study using secondary data from the National Center for Education Statistics, Chen (2009) concluded that barriers to technology adoption includes cost as well as faculty attitudes toward technology (p. 334). While the data were a snapshot from 2000-2001, including 1,500 respondents from 4-year and 2-year colleges, using descriptive statistics to evaluate data, Chen found the information reiterates many of the concerns current researchers continue to report about "barriers to distance education adoption" (p.336) Throughout the study, Chen (2009) referred to technology as TMDE - technology-mediated distance education (p. 334). The dependent variable was the adoption of TMDE and the independent variables represented the barriers, such as costs for program development, equipment, faculty workload, and lack of faculty interest. Chen (2009) concluded that utilizing open source emerging technologies could brighten faculty disposition toward technology-mediated distance education (p. 337). In sum, positive perceived usefulness could impact future faculty use as the ripple effect of those opinions reach prospective adopters of a given technology.

Venkatesh, Morris, Davis, and Davis (2003) conducted "longitudinal field studies at four organizations" that examined user experience and perceived usefulness with new technology to validate the advancement of cumulative Unified Theory of Acceptance and Use of Technology (UTAUT) that is inclusive of several theoretical constructions used to understand user acceptance. Venkatesh et al. "sampled for heterogeneity across technologies, organizations, industries, business functions, and nature of use (voluntary vs. mandatory)" (p. 437). "It is only when one considers the complex range of potential moderating influences that a more complete picture of the dynamic nature of individual perceptions about technology begins to emerge" (Venkatesh et al., 2003, p. 470). The opportunity to use an inclusive model such as UTAUT can provide organizations with a substantive outlook that can be instrumental in making technology adoption decisions.

Researchers in the last couple of years continue to recognize the merits of faculty-perceived usefulness. Schulte (2010) noted that "there was a need for additional research designed to understand faculty use and perceptions of online education technology. Such research for faculty would be greatly beneficial to distance education students, administrators, technology experts, and distance education as a whole" (p. 4). Using a purposive sample of 13 faculty members, Schulte conducted the study at a small midwestern university where students could earn an undergraduate or master's degree by taking courses online (pp. 6-7). Interviews were recorded, coded and analyzed for themes. "Perception categories of instructor course and context, students, interpersonal and 
procedural transactions, learning and teaching transactions, and assessment transactions were needed to bring clarity to existing research and to provide a framework for future, functional research in distance education" (Schulte, 2010, p. 5). These findings support the need to continue research efforts in this area to learn more about education technology perceived usefulness. In Taiwan, teacher attitudes, organizational innovation climate coupled with ease of use were factors discussed in a study of 335 technological and vocational school teachers. Using structural equation modeling (SEM) to identify causal relationships between several variables, Chou, Shen, Hsiao, and Chen (2010) analyzed data from "a 43-item survey questionnaire to measure participants' selfefficacy, uses of technology, and demographic information" (p. 39), and indicated that teacher attitudes influence computer competence and technology use or acceptance: "teachers' perceived innovative culture and job autonomy will enhance teachers' new ideas, evaluations, and implementation of e-teaching" (p. 42). Consequently, Chou et al. suggested that "measures to enhance technological and vocational school teachers' continuous use of e-teaching are as follows: 1) allow teachers to perceive the importance and growing trends in e-learning through teacher studies and job promotions" (p.44). This is useful in that it can help organizations make more appropriate e-tool selections as well as classroom integration recommendation and policy changes.

Zhang and $\mathrm{Xu}$ (2011) also supported the notion of faculty perspectives, specifically perceived usefulness, as salient to discussions about technology adoption. Employing a mental model approach, Zhang and $\mathrm{Xu}$ (2011) submitted how the transition to new technologies can be challenging, and how adoption of new systems is not any easier.

As our definition of perceived compatibility suggests, considerations regarding the compatibility between technologies should extend beyond merely a resemblance between their user interfaces. How they fit users' values and meet users' needs - both of which have been shaped by their experience with legacy technologies - also must be considered. ( $p$. 209)

Their study consisted of an online survey that was emailed to all faculty at the University of Massachusetts in Boston to examine the relationship between user experience and acceptance. Faculty who had no experience using the university's legacy course management system or WebCT, which would be the replacement LMS, were not invited to participate. Zhang and Xu used a structural equation modeling (SEM) approach to analyze the data from 68 respondents who had an average experience with the legacy system of 36.4 months, and 10.33 months with WebCT (p. 205). The purpose of the study was to examine user perceived usefulness, and explore "how perceived compatibility between replacement and legacy technologies affects both mental model processes" (p. 201). In this case, Zhang and Xu wanted to explore how faculty reacted to a course management system switch to WebCT in 2006. Sixty-eight faculty, who may or may not have had previous experience with the legacy CMS at "an urban, public university in a northeastern state of the U.S" responded to an online survey (p. 205). Noteworthy was Zhang's and Xu's interest in learning faculty perspectives "when users switch from a legacy technology to a replacement technology" (p. 201). The theoretical approach used in the study were TAM that suggested that a user's acceptance of a technology is "positively affected by two perceptions: perceived usefulness and perceived ease of use" (p. 202). This concept tapped into the idea that feedback - user experiences with technologycan provide a frame reference that feeds the individual's mental model and can be used in determining technology acceptance. Zhang and Xu (2011) found that "perceived compatibility plays an important role in user acceptance of replacement technologies: the more users consider a 
replacement technology as being compatible with the legacy technology, the more likely they will accept it" (p.208). Zhang and Xu confirmed their hypotheses about the importance of perceived usefulness; "the more users consider a replacement technology as being compatible with the legacy technology, the more likely they will accept it" (p. 208). Furthermore, inquiry about users' prior knowledge with various technologies is salient to determining user technology acceptance.

Gibson, Harris, and Colaric (2008) who also used the TAM to examine faculty perceived usefulness of online education found that the level of familiarity with technologies can perceptions and impact adoption trends, in other words, faculty perceived usefulness influences an individuals intention to use the technology (p. 358).

Across disciplines attitudes toward the use of technology is increasingly being examined to determine levels of acceptance, usability, and sustainability. Kowitlawakul, Chan, Wang, and Wang (2014) examined faculty notions in Singapore about the use of electronic health records in nursing education in an effort to "bridge the gap between educational and clinical settings by training healthcare students to be competent in the use of health information technology (HIT)" (p. 500). They concluded that faculty prior knowledge with the technology is a determining factor in technology integration.

Even though some participants perceived this new technology as a challenge and doubted its capacity to impact on the learning outcomes of students, they also valued it as a new innovation that had a strong potential to train and prepare undergraduate nursing students to be aware of and competent in documenting clinical data electronically (Kowitlawakul, Chan, Wang, \& Wang, 2014, p. 504.)

\section{Faculty Input and Inclusion}

As institutions vet technologies in light of expanding MOOCs and online programs, researchers emphasize how faculty input are salient determinants of technology integration and success. To minimize push-back, faculty opinions about technology are important to decisions involving innovation changes, upgrades, or adoption. A 2013 study examining technology implementation in a graduate management education program noted faculty support as a key success criteria to broad technological acceptance. "Arguably, the single most important element... of the implementation stratagem is faculty "buy in" and orientation.... the general perspective is that it is up to faculty to make the transition as part of the modernization of academia" (Hall, 2013, p. 47).

Faculty input and support concerning technology integration are issues Nicolle and Lou (2008) examined in a mixed-methods study at a Research I university, where 129 faculty members participated. Faculty attitudes toward information technology and stages of adoption of technology survey instruments were used. Nicolle and Lou intimated the negative effects of excluding the input of would-be mainstream users of a technology. "The eventual result is that without the information inputs and other assistance from the change agents, the later adopters are even less likely to adopt" (p. 237). Nicolle and Lou (2008) reiterated the importance of exchanges between change agents and potential users: "that communities of practice are where individuals develop, negotiate, and share the practical, the theoretical, ideals, reality, talking, and doing" (p. 237). Consequently, 
communication and consideration of perceived usefulness are invaluable to discussions and decisions about innovation adoption.

Similarly, Cochrane and Bateman (2010), recipients of the outstanding paper award at the Australian Society for Computers in Learning in Tertiary Education Auckland 2009 conference, asserted that "academic staff development is critical in facilitating the pedagogical focus of this rollout" (p. 12). After 3 years of research with 15 mobile trials, Cochrane and Bateman identified several key categories that impact innovation adoption:

1. The level of pedagogical integration of the technology into the course criteria and assessment.

2. The level of lecturer modeling of the pedagogical use of the tools.

3. The use of regular formative feedback from both lecturers and student peers.

4. Appropriate choice of mobile devices and software.

5. Technological and pedagogical support. (p.12)

Cochrane and Bateman's overview of mobile learning project research suggested that the use of mobile technologies demands ongoing support in order to attain widespread acceptance.

In a qualitative study about technology-enhanced learning environments (TELE), for example, Christiansen and Nyvang (2006) discussed adoption concerns noting the value of potential user feedback and reflection: "If we leave out the innovators and the laggards, some 4/5 of a potential population of adopters can be expected to adopt an innovation, but only if there are external means of motivation" (p. 510). Understanding the mindset and views of the potential user population can assist innovators in productive change efforts that consider the reflections of this demographic. Christiansen and Nyvang concurred with Rogers' diffusion-adoption process and explained how "interpersonal networks with near-peers 'are particularly likely to convey such evaluative information about an innovation' (Rogers, 1995), in which case the setting around the innovation comes into focus" (p. 517). Christiansen and Nyvang (2006) concluded that "management should look for overlapping and complementary needs and values between the stakeholders" (pp.517518). Consideration of multiple stakeholder views regarding innovations can help organizations forecast adoption practices.

A phenomenological study at the University of Glamorgan in the U.K. examined faculty input on the impact of various projects spearheaded over a decade. Davies' (2011) objective was to "reflect on the impact resulting from previous interventions" (p. 3). In the study, Davies (2011) revealed that "a top down mandate for change can be implemented through a bottom-up engagement with practitioners in the language and approaches of their own discipline" [abstract]. In other words, recognition of and alignment with user needs and concerns can assist in moving forward strategic changes at all levels of an institution.

Ping (2010) iterated how teachers are catalysts of change, and, consequently, their opinions, thoughts, and attitudes deserve inclusion. Ping's mixed methods study conducted June 2006 to July 2008 gathered teacher technology perspectives and self-reported use from "a cohort of 118" at the National Institute of Education (NIE) in Singapore and 10 volunteers who participated in focus groups, individual interviews and recorded observations (p. 647). The results focused on only three of the 10 volunteers "who stood out from the rest because they were able to develop a change 
agenda and sustained a constructivist orientation....and extended their influence beyond the classroom by leading school-wide technology initiatives and supporting their university peers in technology integration" (p. 648). The power of faculty input was demonstrated in this study as teachers who were passionately engaged in the use of ICT took it upon themselves to share their perspectives outside of the classroom. One of the quotes from the participants supported this view: I am more interested to convince my peers, my colleagues to use ICT in classroom because I feel that...gradually you will see more students [and] more teachers are willing to use it. If more teachers are willing to use it... management will be more willing to accept. (Ping, 2010, p. 650)

Birch and Burnett (2009) also emphasized the importance of recognizing how attitudes toward a technology can make or break the decision to adopt it, which is invaluable to discussions about technology integration and adoption.

In an exploratory case study, Birch and Bennett (2009), researchers at the University of Southern Queensland (USQ), investigated 'factors that influence academics' adoption and integration of educational technology within e-learning environments" (p. 119). This qualitative study included semi-structured interviews with 14 faculty members ("four pioneers, six early adopters and four non-adopters) and three instructional designers") conducted between March and May in 2006 ( $p$. 119). Among the research questions, "academics were asked about their use of, and attitudes toward, educational technology and what they perceived to be the motivations, enablers and inhibitors associated with the development of e-learning environments" (p. 119). In addition to open lines of communication between early adopters and potential adopters, Birch and Bennet confirmed the relevance of faculty opinions on guidance and leadership, and noted how "the majority of interviewees attributed the lack of widespread development of e-learning environments to a perceived lack of leadership" (p. 123). If organizational leadership or stakeholders are not on board with sufficient knowledge about the proposed technology, change becomes a misguided effort and more challenging to effect. Similarly, in transformational projects that aim to integrate a new tool or system, strategic approaches that involve stakeholders can be most effective.

Understanding faculty perspectives is relevant to adoption studies as the insight can assist change agents. Personal technology use, fear of failure, as well as convenience, also have an impact on how much or little it is used in the classroom. In a study about the impact of faculty rank on technology adoption, Ho Yu, Brewer, Jannasch-Pennell, and DiGangi (2010) concurred with other researchers' findings that point to perception and concerns as impactful on the adoption process. Data from 1,846 faculty were collected in 2007; the online survey employed consisted of " 211 closed-ended and 11 open-ended items" (p. 136) Ho Yu et al. (2010) stated "Without faculty support and interest in using new technologies, investments in the new tools may not lead to anticipated teaching practices and learning outcomes" (p. 132). Using the concern based adoption model (CBAM) HoYu et al. concluded that faculty perspectives should be considered to maximize the adoption as adoption, like change, is a process that happens over time (p. 133). Using a diamond plot, "treated as a visual equivalence to a t-test or ANOVA" (p. 136) to identify patterns, HoYu et al. found technology "adoption follows a path from awareness to passive consumption and...that the initial promotion of technology use should not emphasize the production component, especially if the faculty support is lacking" (p. 140). As a result, for optimal technology adoption, communication exchanges among stakeholders as well as available and adequate support are essential. 


\section{Purposeful Technology and Ease of Use}

Another theme identified in the scholarly articles examined concerns the proposed technology's purposefulness and ease of use. In other words, faculty need to consider the tool's utility in comparison to existing tools, as well as be prepared and willing to participate in training. Keengwe, Kidd, and Kyei-Blankson (2009) stated, "Faculty need to see the perceived ease of use and the perceived usefulness of ICT tools in their teaching practices" (p. 24). In a qualitative narrative study, Keengwe et al. examined 25 narratives at a "large Mid-southern public university" and highlighted several predominant themes: "organizational support, leadership, training and development, and resources" (p. 25). Some of the research questions presented in the study concerning information and communication technology (ICT) were: "(a) How would you describe your experiences in the technology adoption process as it relates to adopting technology for the teaching and learning process? (b) What factors are critical that hinder or influence the technology adoption process? (p.25). Keengwe et al. (2009) believed "data collected ... could help university administration understand the multiple forms of resistance, hindrances, and influences that faculty encounter as part of their daily efforts in adopting and using ICT to support quality teaching" (p. 25). This information can help stakeholders develop a better sense of user needs and desires that impact education technology considerations.

At the University of Ontario's Institute of Technology, Percival and Percival (2009) analyzed perceived value about a laptop leasing learning program's available at the university's liberal arts and technical programs whose goal was to ensure access to technology to all students. The study's objective was to "determine if there is a single model for a laptop program which can efficiently and effectively fulfill the expectations and needs of these diverse populations" (p. 175). An online survey including open-ended and Likert scale questions was conducted to obtain input from students and faculty. Percival and Percival noted that studies of laptop programs rendered mixed results and they desired to learn how perception affects technology decisions. The researchers found that while faculty-perceived usefulness were positive overall and that laptops were considered an asset to instruction, learning about faculty and student concerns provided a broader understanding. Some of the comments included uncertainty about "their ability to adapt to the technology-enhanced environment...and software and hardware compatibility issues" (p. 176). Percival and Percival concluded that critique of a given change is recommended in order to determine whether or not the change is warranted (p. 175). Therefore, feedback is important in the implementation of a program or adoption of new software.

At Linkoping University in Sweden, Persson, Fyrenius, and Bergdahl (2010) compiled the results of three studies at Linkoping University that examined perspectives toward web-enhanced problem based scenarios in group discussion in a 5.5-year medical program. Overall the researchers found that technology integration created enriched learning experiences. Education development using IT (EDIT) is the name of the project that features hundreds of multimedia-enhanced scenarios (p. 766). The study was a multi-year process and included an initial evaluation, online evaluations, 15 observations of five groups, two focus groups, interviews with students, designers and tutors, and two qualitative studies (p. 768). Persson et al. used a "questionnaire including both Likert scale items and open-ended questions was distributed to students (29 out of 31 responded)" (p. 768), and found 
that "the introduction of multi-media-enhanced web based PBL scenarios had positive effects in that it made the group more focused" (p. 770). In sum, the researchers deemed useful learning about perspectives as it could assist in "scrutinizing" instructional technology integration.

Examination of faculty opinions about purposeful technology was also the focus at East Carolina University where instructional podcasting in lieu of text-based media was an approach some faculty used to boost traditional lectures. This strategy was explored at East Carolina University in Greenville, North Carolina by Brown, Brown, Fine, Luterbach, Sugar, and Vinciguerra (2009) who conducted a "cooperative inquiry study in which 11 faculty members [from Library Science and Instructional Technology]...examined their uses of podcasting for instruction" that include "Lecture, Demonstration. Instructions, Elaboration/Clarification, Feedback, Interview, Assignment and Social Presence (p. 351). Brown et al. (2009) found that through regular formal and informal meetings as well as collaborative documentation, faculty users "established a community of practice that encourages social co-participation" (p. 352) that led to in-depth productive discussion about purposeful podcasting uses. Overall, the objective is to understand faculty-perceived usefulness first in order to align pedagogical and instructional demands and needs with organizational change efforts to remain academically competitive and current.

After completing an extensive literature review of e-learning tools from 2001-2006 and conducting interviews with 90 instructors, Heinrich, Milne, and Moore (2009) concluded how e-tools should be considered by faculty to create "formative assessments" (p. 176). Overall, the authors affirmed the importance of user involvement in e-tool choice so that its use is purposeful and aligns with the assignment. For written-based tasks, e-tools can also be instrumental to "provide meaningful feedback, enabling student learning. The literature paints a clear picture of the importance of essaytype student work and the value of formative feedback for supporting learning" (Heinrich et al., 2009, p.186). Ongoing surveys of faculty ideas about instructional technology application can be useful to faculty and researchers to obtain feedback about user acceptance and best practices.

In addition to e-tool utility in the development of formative assessments, faculty can create enriched learning and sharing communities with information and communication technologies (ICTs). Stoltenkamp and Mapuva (2010) noted that "ICTs have the potential to be egalitarian, to bring everyone into a network arrangement. It has the capacity to create community, to provide untold opportunities for communication, exchange and keeping in touch" (p. 211). At University of the Western Cape, South Africa, the authors interviewed the "e-learning team and various academic and institutional leadership ...to determine the extent to which they have benefited from e-learning facilities... as well as the effectiveness and impact of e-learning as a supplement to the traditional mode of educational instruction" (p. 213). While Stoltenkamp and Mapuva (2010) analyzed the use of blogs, and how blogs support reflective, autonomous and interactional learning opportunities, they remarked on the growing and equally dynamic use of other ICTs (p. 213), which can also be applied new disruptive instructional technologies.

Similarly, in an exploratory study at School of Continuing Teacher Education at North-West University, South Africa, Esterhuizen, Blignaut, and Ellis (2013) found that "faculty perceptions at the onset of a transition process from paper-based distance education to e-learning adoption reflected a need for comprehensive practice-based faculty training...Faculty require professional development in order to acquire new competences that enable them to know and to judge why, 
when, and how to use ICT in education." (p. 75-76). Open channels of communication to gauge faculty attitudes toward technologies provide critical insight about the role technology could serve or the gap it can fill as institutions look for ways to streamline, enhance and maximize efficiencies inside and outside of the classroom. Rogers' (1995) discussion of diffusion and adoption iterated how compatibility issues affect acceptance attitudes toward innovation. Consequently, it behooves change agents to learn what concerns and perceived usefulness exist to streamline adoption. In sum, examination of faculty-perceived usefulness is salient to the technology adoption process as the research can reflect insight about how faculty believe the innovation can serve pedagogical objectives and practices.

\section{References}

Akbulut, Y., Odabasi, H., \& Kuzu, A. (2011). Perceptions of preservice teachers regarding the integration of information and communication technologies in Turkish education faculties. Turkish Online Journal of Educational Technology, 10(3), 175-184. Retrieved on 15 February 2016 from http://www.tojet.net/articles/v10i3/10320.pdf

Birch, D. \& Burnett, B. (2009). Bringing academics on board: Encouraging institution-wide diffusion of e-learning environments. Australasian Journal of Educational Technology, 25(1), 117-134. Retrieved on 15 February 2016 from http://www.ascilite.org.au/ajet/ajet25/birch.html

Brown, A., Brown, C., Fine, B., Luterbach, K., Sugar, W., \& Vinciguerra, D. C. (2009). Instructional uses of podcasting in online learning environments: A cooperative inquiry study. Journal of Educational Technology Systems, 37(4), 351-371. doi: 10.2190/ET.37.4.b

Chen, B. (2009). Barriers to adoption of technology-mediated distance education in highereducation institutions. Quarterly Review of Distance Education, 10(4), 333-338. Retrieved on 15 February 2016 from http://www.infoagepub.com/products/Quarterly-Review-ofDistance-Education

Chou, C., Hsiao, H., Shen, C., \& Chen, S. (2010). Analysis of factors in technological and vocational school teachers' perceived organizational innovative climate and continuous use of eteaching: Using computer self-efficacy as an intervening variable. Turkish Online Journal of Educational Technology, 9(4), 35-48. Retrieved on 15 February 2016 from http://eric.ed. gov/?id=EJ908070

Christiansen, E. \& Nyvang, T. (2006). Understanding the adoption of TELEs the importance of management. European Journal of Education, 41(3/4), 509-519. doi:10.1111/j.14653435.2006.00279.x

Cochrane, T. \& Bateman, R. (2010). Smartphones give you wings: Pedagogical affordances of mobile web 2.0. Australasian Journal of Educational Technology, 26(1), 1-14. Retrieved on 15 February 2016 from http://www.ascilite.org.au/ajet/ajet26/cochrane.pdf

Cuban, L. (2001). Oversold and underused: Computers in the classroom. Cambridge, MA: Harvard University Press. 
Davies, C. (2011). Changing academics, changing curriculum: How technology enhanced curriculum design can deliver strategic change. Proceedings of the European Conference on E-Learning, 153-156. Retrieved on 15 February 2016 from http://academic-conferences.org/ecel/ ecel2011/ecel11-proceedings.htm

Esterhuizen, H. D., Blignaut, S., \& Ellis, S. (2013). Looking out and looking in: Exploring a case of faculty perceptions during e-learning staff development. International Review of Research in Open and Distance Learning, 14(3), 59-80.

Gibson, S. G., Harris, M. L., \& Colaric, S. M. (2008). Technology acceptance in an academic context: Faculty acceptance of online education. Journal of Education for Business, 83(6), 355-359.

Hall, O. P., \& Jr. (2013). Assessing faculty attitudes toward technological change in graduate management education. Journal of Online Learning and Teaching, 9(1), 39. Retrieved on 15 February 2016 from http://search.proquest.com/docview/1500385874?accountid=40611

Harasim, L., Hiltz, S., Teles, L., \& Turoff, M. (1995). Learning networks: A field guide to teaching and learning online. Cambridge, Mass: MIT Press.

Heinrich, E., Milne, J., \& Moore, M. (2009). An investigation into e-tool use for formative assignment assessment - status and recommendations. Journal of Educational Technology \& Society, 12(4), 176-192. Retrieved on 15 February 2016 from http://ifets.ieee.org/

Ho Yu, C., Brewer, L, Jannasch-Pennell, A., DiGangi, S. (2010, Summer). Adopting Web 2.0 for instruction: The effects of faculty rank and employment status. Journal of Technology Integration in the Classroom. 2(2), 131-143. Retrieved on 15 February 2016 from http://www.joti.us/

Keengwe, J., Kidd, T., \& Kyei-Blankson, L. (2009). Faculty and technology: Implications for faculty training and technology leadership. Journal of Science Education \& Technology, 18(1), 23-28. doi:10.1007/s10956-008-9126-2

Kowitlawakul, Y., Chan, S., Wang, L., \& Wang, W. (2014). Exploring faculty perceptions towards electronic health records for nursing education. International Nursing Review, 61(4), 499506. doi:10.1111/inr.12141

LeBaron, J. \& McFadden, A. (2008). The brave new world of e-learning: a department's response to mandated change. Interactive Learning Environments, 16(2), 143-156. doi:10.1080/10494820701331079.

Lei, S. A. \& Gupta, R. K. (2010). College distance education courses: Evaluating benefits and costs from institutional, faculty and students' perspectives. Education, 130(4), 616-631. Retrieved on 15 February 2016 from http://www.projectinnovation.com/Education.html

Nicolle, P. S. \& Lou, Y. (2008). Technology adoption into teaching and learning by mainstream university faculty: A mixed methodology study revealing the "how, when, why, and why not". Journal of Educational Computing Research, 39(3), 235-265. doi:10.2190/EC.39.3.c

Percival, J. \& Percival, N. (2009). A case of a laptop learning campus: How do technology choices affect perceptions? ALT-J: Research in Learning Technology, 17(3), 173-186. doi:10.1080/09687760903247633 
Persson, A., Fyrenius, A., \& Bergdahl, B. (2010). Perspectives on using multimedia scenarios in a PBL medical curriculum. Medical Teacher, 32(9), 766-772. doi:10.3109/01421591003688381

Ping, G., Wong, A. L., Choy, D., \& Jing, W. (2010). Developing leadership potential for technology integration: Perspectives of three beginning teachers. Australasian Journal of Educational Technology, 26(5), 643-658. Retrieved on 15 February 2016 from http://www.ascilite. org.au/ajet/ajet26/gao.pdf

Rogers, E. M. (2003). Diffusion of innovations. (5 ${ }^{\text {th }}$ ed.). New York: Free Press.

Schulte, M. (2010). Faculty perceptions of technology distance education transactions: Qualitative outcomes to inform teaching practices. Journal of Educators Online, 7(2). Retrieved on 15 February 2016 from http://www.thejeo.com

Steel, J. \& Hudson, A. (2001). Educational technology in learning and teaching: The perceptions and experiences of teaching staff. Innovations in Education and Teaching International, 38(2), 103-11. doi:10.1080/13558000010030158

Stoltenkamp, J. \& Mapuva, J. (2010). E-Tools and the globalised world of learning and communication. Contemporary Educational Technology, 1(3), 208-220. Retrieved on 15 February 2016 from http://www.cedtech.net/

Zhang, W. \& Xu, P. (2011). Do I have to learn something new? Mental models and the acceptance of replacement technologies. Behaviour \& Information Technology, 30(2), 201-211. doi: 10.1080/0144929X.2010.489665

Correspondence: Alexandra Salas, Director, MercerOnline, Center for Teaching and Learning, Mercer County Community College, West Windsor, New Jersey, USA 